\title{
A CRISE URBANA AMBIENTAL E A CARÊNCIA DO PLANEJAMENTO AMBIENTAL PARA O SANEAMENTO BÁSICO
}

Luís Henrique da Silva Mathias Duarte', Poliana de Oliveira Bassoํ, Mayara Pissutti Albano², Yeda Ruiz Maria².

'Dicentes do curso de Arquitetura e Urbanismo da Universidade do Oeste Paulista - UNOESTE. ${ }^{2}$ Docentes do curso de Arquitetura e Urbanismo da Universidade do Oeste Paulista - UNOESTE.

\section{RESUMO}

O acelerado processo de urbanização no Brasil, com forte crescimento populacional e expansão horizontal das cidades, ocasionou problemas sociais e ambientais urbanos. Esse processo veio acompanhado de um déficit nas políticas públicas de infraestrutura, de habitação, de transportes e de um planejamento urbano ambiental que dirimisse a crise urbana e os impactos ambientais. A carência de habitação levou a ocupação de áreas ilegais e informais por parte das camadas de baixa renda, ambientalmente impactantes e impactadas, por ocuparem muitas vezes áreas de mananciais, encostas de morros, e por não apresentar infraestrutura adequada, principalmente de saneamento básico. Dessa forma, o artigo busca discutir o processo da crise urbana, os problemas ambientais gerados, com foco no saneamento ambiental, e como o Planejamento Urbano Ambiental interfere nesse processo.

Palavras-chave: Planejamento ambiental; saneamento ambiental; resíduos sólidos; esgotamento sanitário.

\section{INTRODUÇÃO E OBJETIVOS}

O Brasil é um país essencialmente urbano, onde mais de $80 \%$ da população vive nas cidades. O seu processo de urbanização ocorreu de maneira acelerada a partir de 1960, e teve seu pico nos anos de 1980. Esse processo de crescimento populacional e expansão urbana ocorreu de forma desordenada, sem planejamento urbano adequado, devido a omissão dos governos Municipais, Estaduais e Federal, e a falta de políticas públicas bem definidas, que resultaram em uma crise urbana, com deficiências em habitação, transporte, saneamento e acesso ao solo urbano, que corroboram para o aumento de moradias ilegais, que ocupam áreas impróprias, como é o caso de ocupações em áreas de mananciais, encostas, Áreas de Preservação Permanente (APPs) e fundos de vale, ocasionando não só problemas urbanos, mas também problemas ambientais (REANI e SEGALLA, 2006).

O intenso processo de urbanização no Brasil pode ser compreendido através dos seguintes dados: a população urbana na década de 1940 era de 26,3\% do total, e em 2000, era de 81,2\%. Em números absolutos: a população urbana correspondia a 18,8 milhões de habitantes contra 130 
milhões no ano 2000. As habitações, em sessenta anos, tiveram que abrigar de 125 milhões de pessoas, sendo 22 milhões delas apenas na última década do século passado (MARICATO, 2001).

Diferente dos países desenvolvidos que tiveram um lento processo de urbanização, levando cerca de duzentos anos, pós Revolução Industrial, o Brasil teve um processo acelerado, que durou cerca meio século, simultaneamente ao processo de industrialização, aumentando drasticamente a sua população urbana e respectivamente o crescimento das cidades (REANI e SEGALLA, 2006).

Para TUCCI (2008), os principais problemas relacionados ao processo de urbanização e infraestrutura nos países em desenvolvimento, como é o caso do Brasil, são: I - as grandes concentrações populacionais em pequenas áreas, com deficiências nos sistemas de infraestrutura e condições ambientais inadequadas que afetam a qualidade de vida desta população, geram impactos ambientais e limitam o desenvolvimento; II -o aumento descontrolado da periferia, acentuado pelo êxodo rural, onde as pessoas migram para as periferias urbanas à procura de empregos, gerando aumento descontrolado dessas regiões que não possuem infraestrutura suficiente, e acabam por aumentar a quantidade de problemas relacionados à segurança e em geral o tráfico de drogas; e III- o planejamento realizado sempre para uma cidade já ocupada, a urbanização espontânea, onde invasões descontroladas ocupam áreas ilegais e de risco. Existe a cidade formal e informal, onde a gestão urbana atente somente a primeira.

A maior parte do crescimento populacional se dá entre as camadas de baixa renda, com isso, há uma tendência de expansão urbana em áreas irregulares ou áreas informais, chegando em algumas cidades a 50\% da total. Segundo Maricato (2001), o processo de urbanização produz maciçamente assentamentos ilegais e consequentemente agressores ao meio ambiente. $\mathrm{Na}$ maioria das cidades brasileiras o número de imóveis ilegais é bastante grande, visto que a cidade legal caminha rumo a se tornar minoria. Santos $(2005$, p.10) afirma que a cidade é o "lugar com mais força e capacidade de atrair gente pobre", mesmo que em muitos casos, em condições subhumanas, e continua: "a pobreza não é apenas o fato do modelo socioeconômico vigente, mas, também, do modelo espacial".

Percebe-se que a crise urbana e ambiental relacionada ao acelerado processo de urbanização e a ocupação de áreas informais e ilegais está diretamente ligada à falta de saneamento ambiental nessas áreas e a ocupação de mananciais, APPs e fundos de vale (REANI e SEGALLA, 2006). Em geral, pode-se considerar que a qualidade do meio ambiente representa um fator decisivo para obtenção de uma melhor qualidade de vida, pois vida e meio ambiente são 
intrínsecos. Ou seja, há uma interação e uma influência mútua entre ambos que varia na escala de tempo e lugar (OLIVEIRA, 1983 apud MACHADO, 1997). A deficiência e a escassez de serviços de saneamento estão diretamente ligadas à contaminação de mananciais superficiais e subterrâneos, pois esse modo de ocupação quase nunca apresenta esgotamento sanitário, levando a problemas ambientais e de saúde pública, com a poluição das águas e em consequência a propagação de doenças (REANI e SEGALLA, 2006).

Visto os problemas urbanos e ambientais enfrentados pelas cidades brasileiras, constata-se que muito se deve a falta de um planejamento ambiental urbano, de modo a melhorar as condições ambientais das cidades e a qualidade de vida. A presente pesquisa busca discutir o conceito de planejamento ambiental urbano e a sua importância para tais melhorias com foco no saneamento ambiental.

\section{METODOLOGIA}

A metodologia seguida foi baseada em levantamentos bibliográficos, onde, através dos quais, buscou-se estudos e produções na área, levando em conta as particularidades do tema abordado. A pesquisa aprofundou a linha teórica onde foram elaborados os conceitos, pressupondo uma avaliação lógica da problemática.

\section{A URBANIZAÇÃO E O PLANEJAMENTO AMBIENTAL URBANO}

No que se refere ao processo de urbanização, uma das maiores dificuldades enfrentadas pela sociedade foi a de adequar as cidades as suas necessidades com o grande crescimento populacional e urbano. No entanto, o homem passa a perceber o comportamento dele com a natureza, e como isso vem afetando a qualidade de vida. Consequentemente, surge a necessidade de enfrentar o modelo exploratório implantado pela Revolução Industrial, que visa apenas o lucro e as vantagens individuais, visando implantar um novo modelo de cidades, cujo objetivo é o de reintroduzir a natureza na cidade, tornando-as sustentáveis (CANEPA, 2007).

Nos anos 1980 que realmente o homem passa a reintroduzir a natureza na cidade, fazendo surgir uma nova modalidade de planejamento, voltada para as intervenções do homem, respeitando a capacidade de suporte dos ecossistemas de modo a preservá-los. Essa modalidade de planejamento denomina-se "Planejamento Ambiental", considerado por FRANCO (2001, p. 35), como: 
[...] o planejamento que parte do princípio da valoração e conservação das bases naturais de um dado território como base de auto-sustentação da vida e das interações que o mantém, ou seja, das relações ecossistêmicas.

Para Floriano (2002 apud PERES e MEDIONDO, 2004), planejamento ambiental é:

[...] um processo de organização de atividades para se chegar a um fim, com fases características e seqüenciais que, em geral, estão na seguinte ordem: identificar o objeto do planejamento, criar uma visão sobre o assunto, definir o objetivo do planejamento, determinar princípios para se atingir o objetivo do planejamento, definir políticas e critérios, estabelecer metas, desenvolver um plano de ações, estabelecer um sistema de monitoramento, controle e análise das ações planejadas, definir um sistema de avaliação e, finalmente, prever a tomada de medidas para prevenção e correção quanto aos desvios que poderão ocorrer em relação ao plano.

Após analisar o processo de urbanização, o início do planejamento ambiental e seu conceito, constata-se que grande parte dos problemas urbanos e ambientais deve-se a percepção tardia por parte do homem da necessidade do planejamento urbano voltado para o ambiente urbano e o ecossistema. A utilização de Planejamentos Ambientais por parte das administrações municipais, estaduais e federais, é essencial para a redução dos problemas que as cidades vêm enfrentado, de modo a propiciar qualidade de vida e qualidade ambiental.

\section{SANEAMENTO AMBIENTAL}

O conceito de saneamento ambiental vem sendo construído ao longo da história da humanidade e consequentemente da urbanização, que recebe definições de acordo com a cultura e o conhecimento de cada época e civilização. A definição utilizada atualmente é:: "o conjunto de medidas que visam a modificar as condições do meio ambiente, com a finalidade de prevenir doenças a saúde" (MENEZES, 1984, p. 26 apud BORJA e MORAES, s.d., p.5).

Para Menezes (1984 apud BORJA e MOARES, s.d.) há uma diferença entre saneamento básico e saneamento ambiental. O saneamento básico restringe ao conceito de ações direcionadas ao controle de patogênicos e seus vetores, enquanto o saneamento ambiental está direcionado ao alcance do equilíbrio ecológico. O saneamento ambiental fica definido segundo a Secretaria Nacional de Saneamento Ambiental, do Ministério das Cidades (s.d. apud BORJA e MORAES, s.d. p. 6):

[...] o conjunto de ações técnicas e socioeconômicas, entendidas fundamentalmente como de saúde pública, tendo por objetivo alcançar 
níveis crescentes de salubridade ambiental, compreendendo o abastecimento de água em quantidade e dentro dos padrões de potabilidade vigentes, o manejo de esgotos sanitários, resíduos sólidos e emissões atmosféricas, a drenagem de águas pluviais, o controle ambiental de vetores e reservatórios de doenças, a promoção sanitária e o controle ambiental do uso e ocupação do solo e prevenção e controle do excesso de ruídos, tendo como finalidade promover e melhorar as condições de vida urbana e rural.

O saneamento ambiental exige grandes investimentos, e poucos municípios foram capazes de empreender. As favelas e os loteamentos periféricos ilegais, apresentam grandes problemas ambientais e de saúde pública devido a falta de infraestrutura urbana, principalmente de saneamento básico. Atualmente $70 \%$ das internações em hospitais públicos advêm de doenças, como a cólera, causadas pela carência dos sistemas adequados, que contaminam a água, que depois é utilizada pela população (RIBEIRO, 1992).

Conclui-se então, segundo BORJA e MORAES (s.d., p. 14), que:

É importante ressaltar, contudo, que a natureza de uma ação de saneamento coloca essa medida como essencial à vida humana e à proteção ambiental. Sendo uma ação eminentemente coletiva, em face da repercussão da sua ausência, ela se constitui em uma meta social. Em sendo uma meta social, essa medida se situa no plano coletivo, onde os indivíduos, a comunidade e o Estado têm papéis a desempenhar. Dada a sua natureza, o esforço para a sua promoção deve-se dar em vários níveis, envolvendo diversos atores. As ações de saneamento, além de serem fundamentalmente de saúde pública e de proteção ambiental, se constituem em serviços essenciais, um direito social do cidadão e dever do Estado. Desse modo, a promoção das ações de saneamento está mais compatível com as políticas públicas e sociais, o que estabelece um princípio fundamental, que deve nortear uma política de saneamento.

O planejamento ambiental e as ações voltadas ao saneamento ambiental, são portanto essencial às cidades, sendo não só uma necessidade dos usuários, mas um direito, cabendo ao Estado a sua implantação em condições adequadas. Para melhor entendimento do que é o saneamento ambiental e as condições no Brasil, dar-se-á a seguir a discussão sobre água e esgotamento sanitário (resíduos líquidos) e resíduos sólidos, partes fundamentais do saneamento básico. 


\section{1 Águas Urbanas}

As águas urbanas englobam o sistema de abastecimento de água e esgotos sanitários, a gestão dos resíduos líquidos, e a drenagem urbana. Atualmente o Brasil vem sofrendo grandes impactos sobre as águas urbanas, relacionados a falta de infraestrutura em seus sistemas, tendo como principais segundo Tucci (2008): a falta de tratamento de esgoto, que são lançados nos corpos d'água, deteriorando a qualidade da água; ausência de redes de drenagem urbana; ocupação dos leitos de inundação ribeirinha; impermeabilização e canalização dos rios urbanos.

A maioria os problemas destacados acima são gerados pela falta de conhecimento por parte da população e principalmente dos profissionais da área que não possuem conhecimento e informações dos problemas e suas causas; concepção inadequada dos profissionais de engenharia para o planejamento e controle dos sistemas, que devido a desatualização dos profissionais em relação a visão ambiental, acabam buscando soluções estruturais que prejudicam e alteram o ambiente, como é o caso do excesso de áreas impermeáveis nas construções; visão setorizada do planejamento urbano, são realizados planejamentos sem relacionar os diferentes componentes da infraestrutura de água; falta de capacidade gerencial, os municípios não apresentam estrutura de planejamento e gerenciamento adequada da água no ambiente urbano (TUCCI, 2008).

\subsection{Esgotamento sanitário}

O sistema de esgotamento sanitário consiste na remoção das águas servidas para uma estação de tratamento: modo adequado; ou o seu lançamento direto ao ambiente: modo inadequado. O objetivo de se implantar esse sistema deve-se a não poluição da água, pois ao serem lançadas em estações de tratamento, a água só é reutilizada ou encaminhada ao ambiente (mananciais de água), depois de tratada. Deste modo garante-se a saúde pública, por evitar a propagação de doenças por águas contaminadas (REANI e SEGALLA, 2006). O lançamento do esgoto sanitário sem tratamento ou com o tratamento insuficiente repercute diretamente ao uso da água, e são originadas tanto nas ligações clandestinas de esgoto, quando na carência de infraestrutura de coleta e tratamento de esgoto (REANI e SEGALLA, 2006).

\subsection{Drenagem Urbana}

A drenagem urbana consiste no sistema preventivo de inundações e impactos nas áreas urbanas, produzidos pelo escoamento pluvial que pode ocorrer de forma isolada ou combinada (TUCCI, 2008). No Brasil, é de competência dos governos municipais a responsabilidade pela 
infraestrutura de drenagem e microdrenagem, cabendo a ele as definições de ações e serviços, que inclui terraplanagem, guias, sarjetas, galerias de águas pluviais, pavimentação, obras de contenção de encostas, e outros meios que minimizam os riscos, prevenindo a inundação das áreas urbanas.

\subsection{Resíduos Sólidos}

Segundo a NBR 10.004 (ABNT 1987), resíduos sólidos são:

Materiais sólidos e semi-sólidos resultantes das atividades da comunidade industrial, doméstica, hospitalar, comercial, agrícola e de serviços de varrição. Também são incluídos lodos provenientes do sistema de tratamento de água, os gerados em equipamentos e instalações de controle de poluição, bem como líquidos cujas particularidades tornem inviável o seu lançamento na rede pública de esgotos ou corpos d'água, ou exijam para isso soluções técnicas e economicamente inviáveis em face à melhor tecnologia disponível.

E são classificados em três classes: Classe I - resíduos sólidos industriais perigosos; Classe II - resíduos sólidos domiciliares; Classe III - entulhos provenientes da construção civil.

Quando gerenciados de forma inadequada, os resíduos sólidos podem resultar em riscos ambientais e de saúde pública, portanto, a sua geração é um dos principais problemas de saneamento ambiental. São muitos os lixos não coletados que acabam sendo dispostos em locais inadequados, escorrendo pelas águas pluviais urbanas e rurais. Além dos lixos não coletados, há também uma grande parcela de lixos que são coletados, mas que são depositados de maneira inadequada em aterros a céu aberto, gerando problemas sanitários e de contaminação hídrica (MOTTA e SAYAGO, 1998).

A situação no Brasil da gestão de resíduos sólidos ainda é bastante problemática, sendo considerada alarmante pelos órgãos e entidades ambientais. Segundo o censo do IBGE (2000, apud CAMPOS; BRAGA e CARVALHO, 2002), a coleta de lixo no país corresponde a 63,8\%, onde $80 \%$ é na zona urbana, e $56 \%$ na zona rural. Porém embora o percentual de coleta não seja tão baixo, o problema está na disposição desses resíduos, visto que apenas $28 \%$ do lixo produzido recebe a destinação adequada.

São necessários cada vez mais recursos para a gestão dos resíduos sólidos, é preciso, portanto estratégias e planejamentos para sua melhoria, como exemplos: internalização dos custos ambientais, o responsável pela produção do resíduo paga, portanto quem produz mais, paga mais; a reciclagem com vantagens ecológicas, economizando matéria-prima e energia; a 
redução do consumo, pois não há necessidades dos grandes consumos do modo de vida capitalista (CAMPOS, BRAGA e CARVALHO, 2012). As soluções dos problemas ocasionados pelos resíduos sólidos, estão ligados, portanto, tanto na melhoria do planejamento e da administração, quanto da educação ambiental e cultural, diminuindo a produção de lixo por parte da população e incentivando a reciclagem.

\section{CONSIDERAÇÕES FINAIS}

Com base nos levantamentos obtidos durante a pesquisa, pôde-se concluir diversos problemas ambientais estão diretamente ligados ao acelerado processo de urbanização que ocasionou o inchaço das cidades e consequentemente os problemas urbanos e ambientais, e também a falta de políticas públicas voltadas para as questões das cidades, e principalmente de um Planejamento Ambiental, que começou a ser pensado tardiamente, refletindo nos problemas de saneamento ambiental encontrados nas cidades brasileiras. É preciso, destarte, organizar e planejar o desenvolvimento das cidades, solucionando em primeira instância os problemas já encontrados, a fim de promover a qualidade de vida urbana e ambiente sustentável, com baixos impactos ambientais.

\section{REFERÊNCIAS}

BORJA, P. C.; MORAES, L. R. S. Saneamento como um Direito Social. Salvador: s.d. Disponível em: <http://www.saneamentobasico.com.br/portal/wp-content/uploads/2013/02/SANEAMENTOCOMO-UM-DIREITO-SOCIAL.pdf>. Acesso em: 06 de jun.

CAMPOS, J. O.; BRAGA, R.; CARVALHO, P. F. Manejo de Resíduos: pressuposto para a gestão ambiental. Rio Claro: LPM/UNESP, 2002. pp. 99-110 / ISBN 85-89154-02-5.

CANEPA, C. Cidades Sustentáveis: O Município como lócus da sustentabilidade. São Paulo: RCS Editora, 2007.

FRANCO, M. de A. R. Planejamento Ambiental para a Cidade Sustentável. SP. Annablume. Editora, 2001.

MACHADO, L. M. C. P. Qualidade Ambiental: indicadores quantitativos e perceptivos. In: MARTOS, H. L. e MAIA, N. B. Indicadores Ambientais. Sorocaba: Bandeirante Ind. Gráfica S.A, 1997.

MARICATO, Ermínia. Brasil cidades: alternativas para a crise urbana. Petrópolis, RJ: Vozes, 2001.

MOTTA, R. S. de.; SAYAGO, D. E. Propostas de Instrumentos Econômicos Ambientais para a Redução do Lixo Urbano e o Reaproveitamento de Sucatas no Brasil. Rio de Janeiro, nov. 1998. 
PERES, R. B.; MEDIONDO, E. M. Desenvolvimento de Cenários de Recuperação como Instrumento ao Planejamento Ambiental e Urbano - bases conceituais e experiências práticas. Seminário NEUR/CEAM, Brasília, DF: 2004.

REANI, R. T.; SEGALLA, R. A Situação do Esgotamento Sanitário na Ocupação Periférica de Baixa Renda em Áreas de Mananciais: Consequências Ambientais no Meio Urbano. Brasília: mai. de 2006.

RIBEIRO, M. A. A Crise Ambiental Urbana Brasileira. Rio de Janeiro: out./dez. 1992.

SANTOS, Milton. A urbanização brasileira. São Paulo: Editora da Universidade de São Paulo, 5ạ ed. 2005.

TUCCI, C. E. M. Águas Urbanas. Vol. 22, no 63, São Paulo: 2008. Disponível em: <http://dx.doi.org/10.1590/S0103-40142008000200007>. Acesso em: 06 de jun. 